\title{
Levels, Bioaccumulation, and Environmental Risk of Polybrominated Diphenyl Ethers around Industry Park in South China
}

\author{
Qinghai Zhang, Zaili Zhang ${ }^{1,2}$, Xiaoshan Jia ${ }^{1,2 *}$ \\ ${ }^{1}$ School of Environmental Science and Engineering, Sun Yat-Sen University, Guangzhou 510275, China \\ ${ }^{2}$ Guangdong Provincial Key Laboratory of Environmental Pollution Control and Remediation Technology, \\ Guangzhou 510275, China
}

Received: 26 November 2014

Accepted: 27 March 2015

\begin{abstract}
Industrial parks are a typical way for economic development in China, which has produced and consumed most polybrominated diphenyl ethers (PBDEs). All samples were collected around an industrial park in May and October 2011, which are extracted XAD-2 and XAD-4 resin and tested by GC-MS (Agilent $7890 \mathrm{~A} / 5975 \mathrm{C}$ ). The mean levels of $\Sigma_{8} \mathrm{PBDE}$ in water, sediment, and soil are $5.53 \mathrm{ng} / \mathrm{ml}, 37.54 \mathrm{ng} / \mathrm{g} \mathrm{dw}$ and $22.08 \mathrm{ng} / \mathrm{g} \mathrm{dw}$, respectively. In vegetable: $\Sigma_{8} \mathrm{PBDE}$ of leaf, stem, and root in water hyacinth are $35.50 \mathrm{ng} / \mathrm{g} \mathrm{dw}$, $52.20 \mathrm{ng} / \mathrm{g} \mathrm{dw}$, and $55.30 \mathrm{ng} / \mathrm{g} \mathrm{dw}$, respectively; and $44.70 \mathrm{ng} / \mathrm{g} \mathrm{dw}, 37.80 \mathrm{ng} / \mathrm{g} \mathrm{dw}$ and $95.10 \mathrm{ng} / \mathrm{g} \mathrm{dw}$ in crabgrass. The level order of organs for vegetables are root $>$ stem $>$ leaf. The levels of PBDE of sediment effect environment more significant than others. The BCF of $\Sigma_{8} \mathrm{PBDE}$ in water hyacinth and crabgrass are 5.46 and 5.15. The mean $\Sigma \mathrm{HQ}$ of PBDE in sediment is 0.25 , indicating low environmental risk.
\end{abstract}

Keywords: PBDE, industrial park, vegetable, bioaccumulation, environment risk

\section{Introduction}

Polybrominated diphenyl ethers (PBDE) are a group of halogenated compounds that include 209 different congeners that vary in both number and position of the bromine atoms. This group of chemicals is widely utilized in electronic, textiles, plastics, furniture, etc., and as three types of commercial PBDEs (penta-BDE, octa-BDE, and deca-BDE). PBDEs are ubiquitous in the environment, and have been detected in air [1], water [2], sediment [3], soil[4], plants [5], birds [6], fish [7], ocean otters [8], dolphins [9], fetal blood, and breastmilk [10, 11]. PBDEs are highly lipophilic, persistent, toxic, and bioaccumulative, which has attracted concern by environmentalists.
However, commercial penta-BDE, octa-BDE, and decaBDE are widely produced and used in China. There are many reports on seriously contaminated areas such as ewaste recycling sites [12] and landfills [13], but there is no report to study the industrial parks from water to terrestrial ecosystems.

Industrial parks are the typical way for economic development in China, which produces and consumes most PBDEs. Zhongkai High-tech Development Park (ZKHDP) is one of the industrial parks in southern China full of electronic, textile, and plastics companies. In our study, we selected ZKHDP to study the level, bioaccumulation, and environment risk of PBDE in water and terrestrial ecosystems.

*e-mail: eesjxs@mail.sysu.edu.cn 


\section{Experiment Procedures}

\section{Sites and Sampling}

ZKHDP is a classical electronic industrial park with good ability to process effluent (more than $90 \%$ of wastewater is treated by WWTP), and is crossed by the Maguodu River, which is a portion of the Tonghu, which finally discharges into the Dongjiang - the main source of drinking water for the Pearl River Delta.

All samples were collected in May and October 2011. The sampling sites are shown in Fig. 1. Water was collected from surface to $0.50 \mathrm{~m}$ deep by an aluminous sampler. Sediment is sampled at the top $5 \mathrm{~cm}$ layer by a stainless steel grab sampler. Soil was collected by a stainless spatula randomly with sampling size $60 \mathrm{~cm} \times 20 \mathrm{~cm}$ (wide $\times$ depth). Vegetables (water hyacinth and cowpea) also were collected randomly. Before extraction, sediment, soil, and vegetable samples were freeze-dried. The vegetable samples were separated into roots, stems, and leaves.

\section{Chemicals}

PBDE Standards (BDE28, BDE47, BDE99, BDE100, BDE153, BDE154, BDE183, and BDE 209) were purchased from AccuStandard (New Haven, CT, USA). XAD resins and other organic reagents were obtained from Sigma (USA). Sodium hydroxide, copper, Silica gel, and so on were obtained from Guangzhou Chemical Reagent Factory.

\section{Extraction and Cleanup}

The procedures of extraction and cleanup for water samples are presented in detail in a previous study [2], where:

1) PBDEs in water are absorbed by XAD-2 and XAD-4 resin (1:1 in weight)
2) the resin is eluted with methanol and a mixture of n-hexane and acetone ( $1: 1$ in volume) by an ultrasonic bath

3) liquid-liquid back extraction

4) removing water

5) solvent exchanged

6) cleaning up and concentrating

Sediment, soil, and vegetable samples were submitted for Soxhlet extraction, which is described elsewhere [3, 14], with a mixture of acetone and hexane (1:1).

\section{Instrumental Analysis}

All samples are detected by GC-MS (Agilent 7890A/5975C) with SIM mode. Mass spectrometer condition is performed by EI $(70 \mathrm{eV})$ with $\mathrm{m} / \mathrm{z} 799$. The separation is performed on two capillary columns (BD-5, 15 $\mathrm{m} \times 0.25 \mathrm{~mm}$ i.d. $\times 0.1 \mu \mathrm{m}$ film thickness for BDE209; 30 $\mathrm{m} \times 0.25 \mathrm{~mm}$ i.d. $\times 0.25 \mu \mathrm{m}$ film thickness for others). The operating parameters of GC-MS have been described previously [15]. Retention time for PBDE congeners are established on standard solutions.

\section{Quality Assurance/Quality Control}

During monitoring procedure performance and matrix effect, ${ }^{13} \mathrm{C}_{12}$-labeled $\mathrm{BDE}$ are spiked as surrogate standards. For instrumental quality control, different samples are spiked with standards of eight targeted PBDEs. The recoveries for water, sediment (including soil), and vegetables are $83.2-105.3 \%, 77.1-110.7 \%$, and $70.7-123.4 \%$, respectively. The limit of detection, defined as three times the signal to noise, ranged from $6 \mathrm{pg} / \mathrm{g}$ to $82 \mathrm{pg} / \mathrm{g}$ for PBDE congeners. Quantification is performed by the external calibration method based on a five-point calibration curve for individual congeners. The correlation coefficients of the calibration curve for eight congeners ranged from 0.9968 to 0.9995 . The concentrations of individual congeners in samples are not corrected for the standard and surrogate standard recovery ratios.

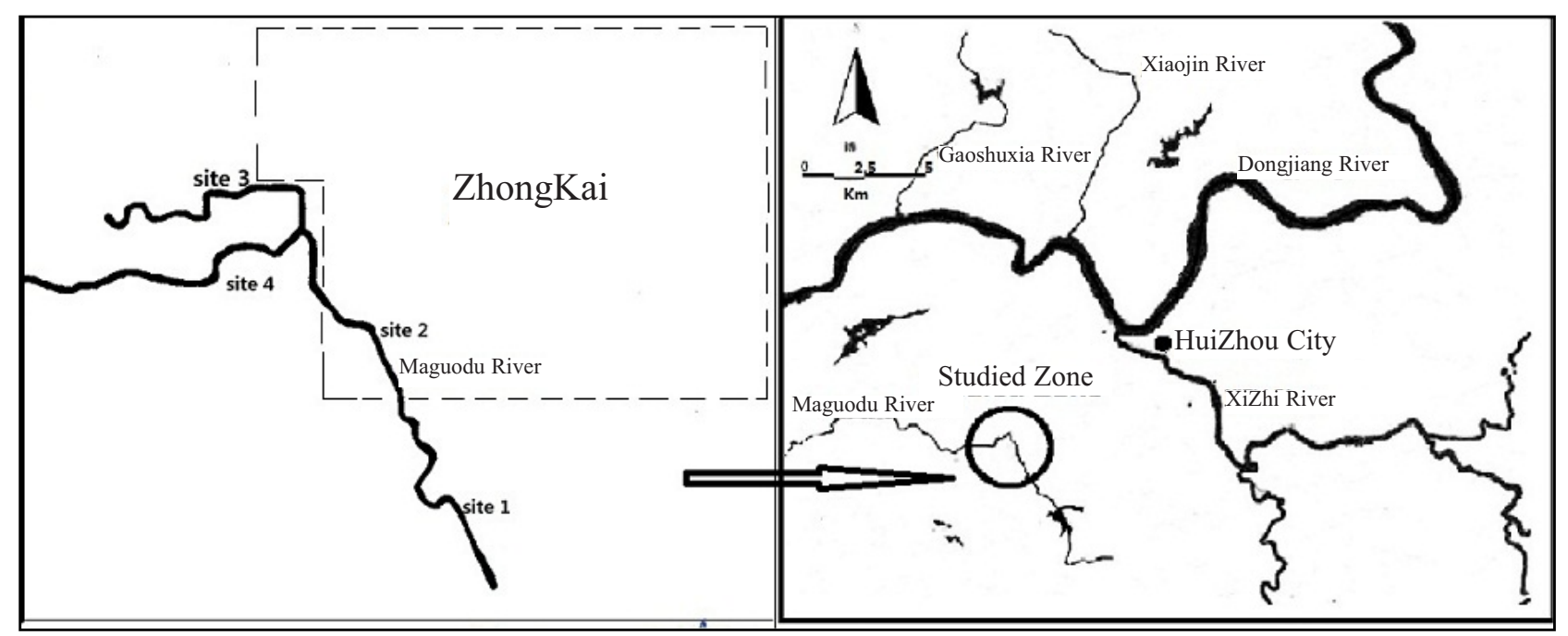

Fig. 1. Map of study area and sampling sites. 
Table 1. PBDE concentrations in water, sediment, and soil around ZKHDP.

\begin{tabular}{|c|c|c|c|}
\hline Congeners & Water $(\mathrm{ng} / \mathrm{ml}), \mathrm{n}=24$ & Sediment $(\mathrm{ng} / \mathrm{g} \mathrm{dw}), \mathrm{n}=24$ & Soil $(\mathrm{ng} / \mathrm{g} \mathrm{dw}), \mathrm{n}=24$ \\
\hline BDE 28 & $1.006(0.642-1.315)^{\mathrm{a}}$ & $2.64(1.15-5.61)$ & $3.27(2.00-5.02)$ \\
\hline BDE 47 & $0.040(0.027-0.054)$ & $1.66(0.91-2.75)$ & $2.02(1.09-3.09)$ \\
\hline BDE 99 & $0.180(0.130-0.249)$ & $1.80(0.81-3.66)$ & $1.42(0.98-2.23)$ \\
\hline BDE 100 & $1.395(0.674-1.987)$ & $1.54(1.04-.222)$ & $1.44(1.08-1.94)$ \\
\hline BDE 153 & $0.047(0.035-0.059)$ & $0.97(0.83-1.20)$ & $1.02(0.77-1.52)$ \\
\hline BDE 154 & $2.801(2.132-3.298)$ & $1.42(0.95-1.85)$ & $1.05(0.79-1.57)$ \\
\hline BDE 183 & $0.031(0.022-0.043)$ & $1.05(0.83-1.27)$ & $11.58(8.50-16.03)$ \\
\hline$\Sigma_{7} \mathrm{PBDE}^{\mathrm{b}}$ & $5.499(3.748-6.718)$ & $26.46(15.08-48.73)$ & $10.51(\mathrm{nd}-12.83)$ \\
\hline BDE209 $^{2}$ & $0.020(0.018-0.022)$ & $11.08(8.13-14.32)$ & $19.46(8.50-31.95)$ \\
\hline$\Sigma_{8} \mathrm{PBDE}^{\mathrm{c}}$ & $5.519(3.767-6.740)$ & $37.54(23.29-61.52)$ & \\
\hline
\end{tabular}

${ }^{\mathrm{a}}$ mean (range);

${ }^{\mathrm{b}}$ sum of BDE 28, BDE 47, BDE 99, BDE 100, BDE 153, BDE 154, and BDE 183.

${ }^{\mathrm{c}}$ sum of BDE 28, BDE 47, BDE 99, BDE 100, BDE 153, BDE 154, BDE 18, and BDE 209;

nd - not detected; dw - dry weight

\section{Results and Discussion}

Levels

The mean levels of BDE154, $\Sigma_{7} \mathrm{PBDE}$, and $\Sigma_{8} \mathrm{PBDE}$ in water are $2.80 \mathrm{ng} / \mathrm{ml}, 5.50 \mathrm{ng} / \mathrm{ml}$, and $5.52 \mathrm{ng} / \mathrm{ml}$, respectively. Others are shown in Table 1. The top three PBDE congeners are BDE154 (50.73\%), BDE100 (25.28\%), and BDE28 (18.23\%). The profiles of others are shown in Fig. 2. The levels of BDE209, $\Sigma_{7} \mathrm{PBDE}$, and $\Sigma_{8} \mathrm{PBDE}$ in our report are higher than in the Dongjing River [16]. Furthermore, the PBDEs of the Maguodu enter the Dongjing. The PBDE lev- els in our report, excluding BDE 209, are higher than those of the Gwangyang Bay in Korea [17], which is surrounded by industrial complexes for steel, petrochemicals, and so on, from 1.38- to 3,179-fold, and 117- and 41-fold for $\Sigma_{7} \mathrm{PBDE}$ and $\Sigma_{8} \mathrm{PBDE}$. At the same time, our report is higher than the $\mathrm{Ob}$ and Yenisei rivers in Russia [18]. But it is lower than those of heavy contamination sites: the Pearl River Estuary [19], a landfill in Cape Town [20], and an e-waste site in Taizhou [12]. The PBDE level of water is significantly correlated with those of water hyacinth $(\mathrm{R}=0.325, \mathrm{p}<0.05)$, others are shown in Table 2. This indicates that the PBDE in water affect water hyacinth significantly.

Congener profiles of PBDE in each type of sample

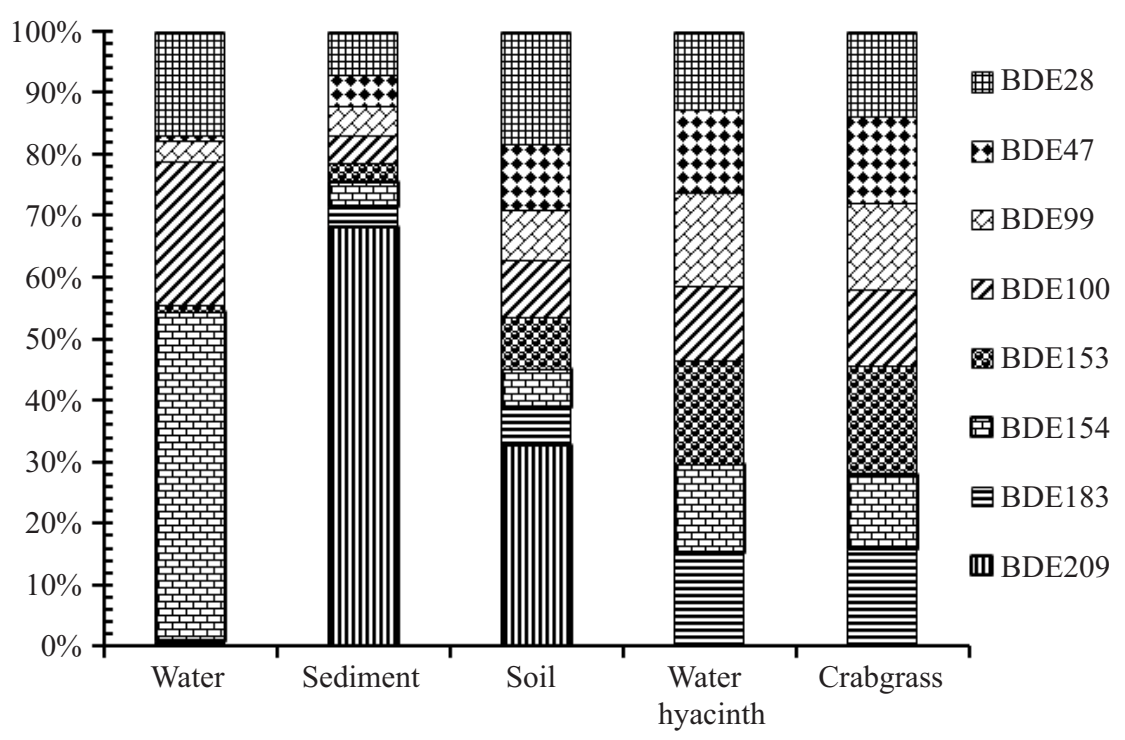

Fig. 2. Average composition of individual PBDEs in water, sediment, soil, water hyacinth, and crabgrass around ZKHDP. 
Table 2. Pearson's correlation coefficients between different environmental media.

\begin{tabular}{|l|c|c|c|c|c|}
\hline & Water & Sediment & Bank soil & Water hyacinth & Crabgrass \\
\hline Water & 1.00 & 0.22 & 0.20 & $0.325^{*}$ & 0.31 \\
\hline Sediment & & 1.00 & $0.802^{* *}$ & $0.739^{* *}$ & $0.846^{* *}$ \\
\hline Bank soil & & & 1.00 & $0.675^{* *}$ & $0.680^{* *}$ \\
\hline Water hyacinth & & & & 1.00 & $0.906^{* *}$ \\
\hline Crabgrass & & & & & 1.00 \\
\hline
\end{tabular}

*it is significance level at 0.05 ;

$* *$ it is significance level at 0.01

Table 3. Concentrations of PBDE in water hyacinth and crabgrass around ZKHDP (ng/g dw).

\begin{tabular}{|l|c|c|c|c|c|c|}
\hline \multirow{2}{*}{ Congeners } & \multicolumn{3}{|c|}{ Water hyacinth } & \multicolumn{3}{c|}{ Crabgrass } \\
\cline { 2 - 7 } & leaf $(\mathrm{n}=4)$ & stem $(\mathrm{n}=4)$ & $\operatorname{root}(\mathrm{n}=4)$ & leaf $(\mathrm{n}=4)$ & stem $(\mathrm{n}=4)$ & root $(\mathrm{n}=4)$ \\
\hline BDE 28 & $5.04(3.43-7.02)$ & $8.42(5.51-11.17)$ & $8.52(6.46-12.47)$ & $6.02(4.27-7.87)$ & $5.00(3.35-7.21)$ & $13.09(7.8-21.1)$ \\
\hline BDE 47 & $4.86(3.56-5.71)$ & $7.32(5.62-8.26)$ & $7.68(5.15-9.21)$ & $7.03(4.77-10.6)$ & $5.93(3.81-8.45)$ & $14.57(7.7-18.2)$ \\
\hline BDE 99 & $5.32(2.71-7.80)$ & $7.16(4.11-9.88)$ & $8.51(5.12-11.85)$ & $6.54(4.85-8.49)$ & $6.15(3.85-9.32)$ & $13.77(7.9-20.1)$ \\
\hline BDE 100 & $3.85(2.37-5.02)$ & $5.94(4.24-7.63)$ & $6.47(3.84-8.05)$ & $4.99(4.04-7.38)$ & $4.33(3.26-7.39)$ & $10.49(6.9-17.8)$ \\
\hline BDE 153 & $6.00(4.31-6.81)$ & $8.58(6.50-9.99)$ & $10.22(7.28-12.35)$ & $7.80(6.10-10.4)$ & $6.69(4.85-10.43)$ & $16.28(9.6-25.9)$ \\
\hline BDE 154 & $5.16(4.42-6.24)$ & $7.01(5.68-8.34)$ & $7.17(6.09-8.13)$ & $5.46(4.08-7.31)$ & $4.62(3.28-7.33)$ & $12.40(6.8-18.2)$ \\
\hline BDE 183 & $5.27(3.82-6.14)$ & $7.82(5.92-9.10)$ & $9.20(6.85-10.72)$ & $6.88(5.48-9.17)$ & $5.07(4.03-9.26)$ & $14.47(8.7-22.5)$ \\
\hline BDE 209 & nd & nd & nd & $n d$ & nd & nd \\
\hline$\Sigma_{7}$ PBDE & $35.50(25.34-42.10)$ & $52.20(38.3-61.86)$ & $55.30(41.0-69.9)$ & $44.70(34.2-57.5)$ & $37.80(24.2-58.61)$ & $95.10(55.4-145.25)$ \\
\hline
\end{tabular}

nd - not detected

Deposited sediment is suspended for a long time, which could present a contamination degree better than water. The mean levels of BDE 209, $\Sigma_{7} \mathrm{PBDE}$, and $\Sigma_{8} \mathrm{PBDE}$ in sediment are $11.08 \mathrm{ng} / \mathrm{g} \mathrm{dw}, 26.46 \mathrm{ng} / \mathrm{g} \mathrm{dw}$, and 37.54 $\mathrm{ng} / \mathrm{g}$ dw. Others are shown in Table 1. BDE 209 is predominant with $29.52 \%$. Others are shown in Fig. 2. Compared with other reports in the world, the $\Sigma_{7} \mathrm{PBDE}$ and $\Sigma_{8}$ PBDE levels in our report are higher than in the Xijiang River and the Pearl River Estuary [3]. The PBDE congeners levels, excluding BDE 209, are higher than those of the Dongguan stretch of the Dongjiang River [21], because Dongguan is the electronic products manufacturing center of the world [3]. Furthermore, the results in this study are higher than those of Bo Sea [15], the Prédecelle River [22], and Gwangyang Bay [17]. But the levels of BDE 209, $\Sigma_{7} \mathrm{PBDE}$, and $\Sigma_{8} \mathrm{PBDE}$ in our report are lower than those of the Zhujiang River in Guangzhou reach and the Dongjiang River in Donguan reach [3], Guiyu Town [23], and the Hyco River [24]. Sediment is significantly correlated with bank soil, water hyacinth, and crabgrass at the 0.01 level, with detailed information shown in Table 2. This indicates that the levels of PBDE in sediment effect water and the terrestrial ecosystem significantly. The PBDE of sediment around ZKHDP is from the industries in it. Furthermore, PBDE levels of sediment in our reports are higher than many reports in the world, so ZKHDP significantly affects the level of PBDE in sediment.

Soil is an important present index in terrestrial ecosystems. The mean levels of BDE 209, $\Sigma_{7} \mathrm{PBDE}$, and $\Sigma_{8} \mathrm{PBDE}$ in bank soil are $10.51 \mathrm{ng} / \mathrm{g} \mathrm{dw}, 11.58 \mathrm{ng} / \mathrm{g} \mathrm{dw}$, and 19.46 $\mathrm{ng} / \mathrm{g} \mathrm{dw}$, respectively; others are shown in Table 1 . The top three PBDE congeners in percentage are BDE 209 (47.58\%), BDE 28 (14.81\%), and BDE 47 (9.15\%); others are shown in Fig. 2. PBDE levels in our report are higher than those of Chongming Island [25] and the Yellow River Delta [26]. Furthermore, PBDE levels in this paper, excluding BDE183, are higher than those of soil along the Shiawassee River with heavy industries [27] and Tibetan Plateau soil [28]. But the results in our report are lower than those of Dongguan (the world's largest electronic manufacturing base), Foshan (a center of plastics and electronics manufactures), and Zhongshan (a center of textile, garment, and electronic industries) [29]. Bank soil is significantly correlated with sediment $(\mathrm{R}=0.8002$, at 0.01 level), others are shown in Table 2. This indicates that the level of PBDE in bank soil is significantly affected by sediment, and the PBDE in sediment is from ZKHDP. At the same time, the results in our report are higher than many reports in the world, but lower than some reports on e-waste and high- 
Table 4. Hazard quotients (HQs) of PBDEs for sediment $\left(\times 10^{-2}\right)$.

\begin{tabular}{|l|c|c|c|c|c|}
\hline \multicolumn{1}{|c|}{ Congeners } & Site 1 & Site 2 & Site 3 & Site 4 & Mean \\
\hline Penta-BDE & 15.48 & 31.39 & 22.81 & 28.87 & 24.64 \\
\hline Octa-BDE & 0.04 & 0.04 & 0.03 & 0.04 & 0.04 \\
\hline Deca-BDE & 0.02 & 0.04 & 0.02 & 0.06 & 0.04 \\
\hline$\Sigma$ HQ & 15.54 & 31.47 & 22.86 & 28.97 & 24.71 \\
\hline
\end{tabular}

density industrial zones. All of the above show that bank soil are influenced by ZKHDP significantly.

Water hyacinth and crabgrass are selected as the model plants in water and soil ecosystems, respectively. PBDE congeners, excluding BDE 209, are detected in all organs (root, stem, and leaf). In the water hyacinth the mean levels of BDE 153, BDE 183, and $\Sigma_{7} \mathrm{PBDE}$ for leaf are 6.00, 5.27, and $35.50 \mathrm{ng} / \mathrm{g} \mathrm{dw}$, respectively; $8.58,7.82$, and $52.20 \mathrm{ng} / \mathrm{g}$ $\mathrm{dw}$ for stem; and 10.22, 9.20, and $55.30 \mathrm{ng} / \mathrm{g} \mathrm{dw}$ for root. The top three percentages of PBDE in the whole are BDE 153 (17.04\%), BDE 183 (15.32\%), and BDE 28 (15.11\%); others are shown in Fig. 2. The PBDE level orders of organs is root $>$ stem $>$ leaf. The correlation coefficient of water hyacinth for water and sediment are $0.325(\mathrm{p}<0.05)$ and $0.739(\mathrm{p}<0.01)$, which shows that the PBDE in water and sediment significantly affects those of water hyacinth. In the crabgrass, the mean levels of BDE 153, BDE 183, and $\Sigma_{7} \mathrm{PBDE}$ for leaf are $7.80,6.88$, and $44.70 \mathrm{ng} / \mathrm{g} \mathrm{dw}$, respectively; $6.69,5.07$, and $37.80 \mathrm{ng} / \mathrm{g} \mathrm{dw}$ for stem; and 16.28, 14.47 , and $95.10 \mathrm{ng} / \mathrm{g} \mathrm{dw}$ for root. The top three PBDE congeners in the whole are BDE 153 (17.31\%), BDE 47 (15.41\%), and BDE 183 (15.24\%). The profiles of others are shown in Fig. 2. The PBDE level order of organ is root $>$ stem $>$ leaf. The correlation coefficients of crabgrass for water, sediment, and soil are $0.31,0.846(\mathrm{p}<0.01)$, and 0.680 $(\mathrm{p}<0.01)$, respectively, which shows that the PBDE in sediment and soil significantly affected those of crabgrass.

There are few reports on vegetables. The PBDE levels, excluding BDE 209, for leaves in our study are higher than those of Solidago altissima and Phragmites australis in Shanghai [30], and Cinnamomum camphora in Taizhou (e-waste) [31]. The average $\Sigma$ PBDE level of leaf for water hyacinth is approximately from 2- to 15 -fold to Solidago altissima, Phragmites australis, Cinnamomum camphora, and pasture [32]; and from 3- to 19-fold for crabgrass. All of these indicated that the levels of PBDE around ZKHDP are higher than most reports from around the world. There are no significant predominant PBDE congeners in the organs of water hyacinth and crabgrass. It is not consistent with other reports. Some reports [33] showed that BDE 209 is the predominant congener, while some reports [34] regarded that the lower brominated congeners are dominant congeners such as BDE 99 and/or BDE 47. The variations of the congener profile in different plants are due to the difference of species and the living environment. The correlation coefficients of PBDE between sediment and vegetable around ZKHDP show that the vegetable in water and terrestrial ecosystem around ZKHDP are influenced significantly by sediment, which in the case of PBDEs are from the industries in ZKHDP, so ZKHDP affects the PBDE levels in vegetables significantly.

\section{Bioaccumulation}

Bioconcentration factor $(\mathrm{BCF})$ is one of the most important indexes to evaluate environmental risk of contamination. The BCF method referred to [35] US EPA (1999).

$$
\mathrm{BCF}=\frac{C_{\text {root }}}{C_{\text {soil }}}
$$

...where $C_{\text {root }}$ is the concentration of PBDE in root (ng/g $\mathrm{dw}$ ), and $C_{\text {soil }}$ is the concentration of PBDE in soil. For water hyacinth $C_{\text {soil }}$ is used by PBDE concentration in sediment, because the solubility of PBDE is very low in water. Furthermore, water hyacinth is corrected near store, most of root of water hyacinth reached sediment. So the concentration of PBDE in sediment is workable.

The BCF of PBDE in water hyacinth and crabgrass presented bioaccumulation levels of vegetable in water and terrestrial ecosystem. The BCF mean of BDE 153, BDE 183 and $\Sigma_{7} \mathrm{PBDE}$ for Crabgrass are 7.26, 9.00, and 5.15, respectively; and $7.51,8.83$, and 5.46 for water hyacinth. The BCF of BDE 183 is higher than other congeners in both vegetables. BCF of $\Sigma_{7} \mathrm{PBDE}$ for water hyacinth is a little higher than those of crabgrass. But FCF doesn't increase linearly with the level of sediment, because the different species in different environments result in different BCF. BCF in crabgrass, excluding BDE 209 (no detection), is higher than rice near an e-waste recycling site in Qingyuan [36]. Furthermore, crabgrass's BCFs are higher than those of Kandelia obovata and Avicennia marina in BDE 28 and BDE 47 [37], and tobacco and nightshade in BDE 47, BD 99, and BDE 100 [34]. This indicates that ZKHDP seriously affected the $\mathrm{BCF}$ in water and terrestrial ecosystems.

BCF are calculated by the data from Table 3, which mean the level of PBDE of root from Water hyacinth and Crabgrass.

\section{Environmental Risk}

Assessment of PBDE in environmental media is a very important method to evaluate PBDE environmental risk. PBDEs in the environment are from commercial pentaBDE, octa-BDE, and deca-BDE. There are no PNEC for each PBDE congener. The report of Guardia et al. [38] indicated that the main congener of commercial penta-BDE, octa-BDE, and deca-BDE are BDE-47, -99, -100; BDE153, -183, -197; and BDE209, respectively. Here BDE-28, $-47,-99,-100$; BDE153, $-154,-183$, and BDE209 presented penta-BDE, octa-BDE, and deca-BDE, respectively.

Sediment is an important index to assess environmental risk. We Estimated hazard quotients (HQ) of sediments by the EPA (1994) [39]. 


$$
\mathrm{HQ}=\frac{C}{P N E C}
$$

...where $C$ is PBDE concentration, $P N E C$ is predicted noeffect concentrations [39] (EPA, 1994), and PNEC of penta-BDE, octa-BDE, and deca-BDE are $0.031,9.10$, and $76 \mathrm{mg} / \mathrm{kg}$ [40]. For interpretation, an $\mathrm{HQ}<0.1$ indicates no hazard, 0.1-1 a low hazard, 1-10 a moderate hazard, and $>10$ a high hazard [41].

The mean HQs (Table 4) of penta-BDE, octa-BDE, and deca-BDE in sediment are $0.25,0.04 \times 10^{-2}$, and $0.04 \times 10^{-2}$, respectively. The $\Sigma H Q$ ranged from 0.16 to 0.31 with mean 0.25 (HQ is between 0.1 and 1.0, which indicates low environmental risk), which showed low environmental risk for PBDE. The HQs of penta-BDE, octa-BDE, and deca-BDE in our report are higher than those of the Huangpu River, Suzhou Creek, and Yunzao Creek (excluding the HQ of octa-BDE in Suzhou on the same level) [42]. This indicates that the HQs of the Maguodu River are higher than the Yangtze. Therefore, the environmental risk of PBDE in the Maguodu is damaged more seriously by those companies in the ZKHDP.

\section{Conclusion}

The PBDEs were detected both in water and on the terrestrial ecosystem, which included water, sediment, soil, and plants (water hyacinth and crabgrass). The levels of sediment were higher than those of bank soil. And the level of water, sediment, and soil in our report were higher than those of some e-waste sites and many other places, but lower than those of heavily contaminated sites. The levels of PBDE congeners (excluding BDE 209) in water hyacinth and crabgrass were even higher than those of plants in e-waste sites, landfills, and so on. In plants, the level of order in organ was root $>$ stem $>$ leaf, which was as other reports, but there were no significantly predominant congeners. The predominant congeners of liquid and solid (sediment and soil) were BDE 154 and BDE 209, respectively. But the predominant congener of plants is BDE 154. The $\Sigma$ HQs of PBDE of sediment ranged from 0.1 to 1 , which indicates lower environment risk. Even the levels of PBDE congeners (more than $90 \%$ effluent was treated by WWTP) were not as significant as some reports, but it still showed the significant contamination effect of PBDE from ZKHDP, and was with significant potential environment risk in PBDE.

\section{Acknowledgements}

This work is supported in part by a Grant from the Environmental and Pollution Control Technology and National Key Scientific and Technological Project "Water Pollution Control and Treatment" (2012ZX07206002 and 2012ZX07206004).

\section{References}

1. JOHNSON P.I., STAPLETON H.M., SJODIN A., MEEKER J.D. Relationships between Polybrominated Diphenyl Ether Concentrations in House Dust and Serum. Environ. Sci. Technol. 44, 5627, 2010.

2. GUAN Y.F., WANG J.Z., NI H.G., LUO X.J., MAI B.X., ZENG E.Y. Riverine Inputs of Polybrominated Diphenyl Ethers from the Pearl River Delta (China) to the Coastal Ocean. Environ. Sci. Technol. 41, 6007, 2007.

3. MAI B.X., CHEN S.J., LUO X.J., CHEN L.G., YANG Q.S., SHENG G.Y., PENG P.G., FU J.M., ZENG E.Y. Distribution of polybrominated diphenyl ethersin sediments of the Pearl River Delta and adjacent South China Sea. Environ. Sci. Technol. 39, 3521, 2005.

4. ZOU M.Y., RAN Y., GONG J., MAI B.X., ZENG E.Y. Polybrominated diphenyl ethers in watershed soils of the Pearl River Delta, China: occurrence, inventory, and fate. Environ. Sci. Technol. 41, 8262, 2007.

5. LAKE I.R., FOXAL C.D., FERNANDS A., LEWIS M., ROSE M., WHITE O., DOWDING V. Effects of River Flooding on Polybrominated Diphenyl Ether (PBDE) Levels in Cows' Milk, Soil, and Grass. Environ. Sci. Technol. 45, 5017, 2011.

6. CHEN D., MAI B.X., SONG J., SUN Q.H., LUO Y., LUO X.J., ZENG E.Y., HALE R.C. Polybrominated diphenyl ethers in birds of prey from Northern China. Environ. Sci. Technol. 41, 1828, 2007.

7. STASKAL D.F., SCOTT L.L.F., HAWS L.C., LUKSEMGUR W.J., BIRNBAUM L.S., URBAN J.D., PAUSTENBACH D.J., HARRIS M.A. Assessment of Polybrominated Diphenyl Ether Exposures and Health Risks Associated with Consumption of Southern Mississippi Catfish. Environ. Sci. Technol. 42, 6755, 2008.

8. POUNTNEY A., FILBY A.L., THOMAS G.O., SIMPSON V.R., CHADWICK E.A., STEVENS J.R., TYLER C.R. High liver content of polybrominated diphenyl ether (PBDE) in otters (Lutra lutra) from England and Wales. Chemosphere, 118, 81, 2015.

9. LEONEL J., SEICANO J.L., SECCHI E.R., BERTOZZI C., FILLMANN G., MONTONE R.C. PBDE levels in franciscana dolphin (Pontoporia blainvillei): Temporal trend and geographical comparison. Sci. Total. Environ. 493, 405, 2015.

10. BI X.H., QU W.Y., SHENG G.Y., ZHANG W.B., MAI B.X., CHEN D.J., YU L., FU, J.M. Polybrominated diphenyl ethers in South China maternal and fetal blood and breastmilk. Environ. Pollut. 144, 1024, 2006.

11. STASINSKA A., HEYWORTH J., REID A., CALLAN A., ODLAND J. Ø., DUONG P.T., HO V.Q., HINWOOD A. Polybrominated diphenyl ether (PBDE) concentrations in plasma of pregnant women from Western Australia. Sci. Total. Environ. 493, 554, 2014.

12. WANG J.X., LIN Z.K., LIN K.F., WANG C.Y., ZHANG W., CUI C.Y., LIN J.D., DONG Q.X., HUANG C.J. Polybrominated diphenyl ethers in water, sediment, soil, and biological samples from different industrial areas in Zhejiang, China. J. Hazard. Mater. 197, 211, 2011.

13. LI Y., LI J.H., DENG C. Occurrence, characteristics and leakage of polybrominated diphenyl ethers in leachate from municipal solid iste landfills in China. Environ Pollut. 184, 94, 2014.

14. VOORSPOELS S., COVACI A., SCHEPENS P. Polybrominated diphenyl ethers in marine species form the Belgian North Sea and the Western Scheldt Estuary: levels, 
profiles and distribution. Environ. Sci. Technol. 37, 4348, 2003.

15. WANG Z., MA X.D., LIN Z.S., NA G.S., YAO Z.W. Congener specific distributions of polybrominated diphenyl ethers (PBDEs) in sediment and mussel (Mytilus edulis) of the Bo Sea, China. Chemosphere. 74, (7), 896, 2009.

16. HE M.J., LUO X.J., CHEN M.Y., SUN Y.X., CHEN S.J., MAI B.X. Bioaccumulation of polybrominated diphenyl ethers and decabromodiphenyl ethane in fish from a river system in a highly industrialized area, South China. Sci. Total Environ. 419, 109, 2012.

17. KIM Y.H., KIM H.S., CHOI H.G., CHO H.S., MOON H.B. Contamination and Bioaccumulation of Polybrominated Diphenyl Ethers (PBDEs) in Gwangyang Bay, Korea. Toxicol. Environ. Health Sci. 4, (1), 42, 2012.

18. CARROLL J., SAVIONV V., SAVINOVA T., DAHLE S., MCCRA R., MUIR D.C.G. PCBs, PBDE and pesticides released to the Arctic Ocean by the Russian rivers $\mathrm{Ob}$ and Yenisei. Environ. Sci. Technol. 42, 69, 2008.

19. GUAN Y.F., SOJINU O.S.S., LI S.M., ZENG E.Y. Fate of polybrominated diphenyl ethers in the environment of the Pearl River Estuary, South China. Environ. Pollut. 157, 2166, 2009.

20. DASO A.P., FATOKI O.S., ODENDAAL J.P., OLUJIMI O.O. Polybrominated diphenyl ethers (PBDEs) and 2,2',4,4',5,5'-hexabromobiphenyl (BB-153) in landfill leachate in Cape Town, South Africa Adegbenro. Environ Monit Assess. 185, 431, 2013.

21. ZHANG X.L., LUO X.J., CHEN S.J., WU J.P., MAI B.X. Spatial distribution and vertical profile of polybrominated diphenyl ethers, tetrabromobisphenol A, and decabromodiphenyl ethane in river sediment from an industrialized region of South China. Environ Pollut. 157, 1917, 2009.

22. LABADIE P., TLILI K., ALLIOT F., BOURGE C., DESPORTES A., CHEVREUIL M. Development of analytical procedures for trace-level determination of polybrominated diphenyl ethers and tetrabromobisphenol $\mathrm{A}$ in river water and sediment. Anal. Bioanal. Chem. 396, (2), 865, 2010.

23. LUO Q., CAI Z.W., WONG M.H. Polybrominated diphenyl ethers in fish and sediment from river polluted by electronic iste. Sci. Total Environ. 383, (1-3), 115, 2007.

24. GUARDIA M.J.L., ROBERT C., HALE R.C., HARVEY E. Evidence of Debromination of Decabromodiphenyl Ether (BDE-209) in Biota from a istewater Receiving Stream. Environ. Sci. Technol. 47, (19), 6663, 2007.

25. DUAN Y.P., MENG X.Z., YANG C., PAN Z.Y., CHEN L., YU R., LI F.T. Polybrominated diphenyl ethers in background surface soils from the Yangtze River Delta (YRD) China: occurrence, sources, and inventory. Environ Sci Pollut R. 17, (4), 948, 2010.

26. CHEN C.E., ZHAO H.X., CHEN J.W., QIAO X.L., XIE Q., ZHANG Y.F. Polybrominated diphenyl ethers in soils of the modern Yellow River Delta, China:Occurrence, distribution and inventory. Chemosphere. 88, 791, 2012.

27. YUN S.H., ADDINK R., MCCABE J.M., OSTASZEWSKI A., MACKENZIE-TAYLOR D., TAYLOR A.B., KANNAN K. Polybrominated diphenyl ethers and polybrominated biphenyls in sediment and floodplain soils of the Saginaw River watershed, Michigan, USA. Arch Environ Con. 55, (1), $1,2008$.

28. ZHENG X.Y., LIU X.D., JIANG G.B., WANG Y.W., ZHANG Q.H., CAI Y.Q., CONG Z.Y. Distribution of PCBs and PBDEs in soils along the altitudinal gradients of Balang Mountain, the east edge of the Tibetan Plateau. Environ Pollut. 161, 101, 2012.
29. GAO S.T., HONG J.W., YU Z.Q., WANG, J.Z., YANG G.Y., SHENG G.Y., FU J.M. Polybrominated Diphenyl Ethers in Surface Soils from E-Waste Recycling Areas and Industrial Areas in South China:Concentration Levels, Congener Profile, and Inventory. Environ. Toxicol. Chem. 30, (12), 2688, 2011.

30. HUANG K., GUO J., LIN K.F., ZHOU X.Y., WANG J.X., ZHUO P., XU F., ZHANG M.L. Distribution and temporal trend of polybrominated diphenyl ethers in one Shanghai municipal landfill, China. Environ Sci Pollut Res. 20, 5299, 2013.

31. MA J., ADDINK R., YUN S.H., CHENG J.P., WANG W.H., KANNAN K. Polybrominated Dibenzo-p-dioxins/ Dibenzofurans and Polybrominated Diphenyl Ethers in Soil, Vegetation, Workshop-Floor Dust, and Electronic Shredder Residue from an Electronic iste Recycling Facility and in Soils from a Chemical Industrial Complex in Eastern China. Environ. Sci. Technol. 43, (19), 7350, 2009.

32. PAROLINI M., GUAZZONI N., BINELLI A., TREMLADA P. Polybrominated Diphenyl Ether Contamination in Soil, Vegetation, and Cow Milk From a High-Mountain Pasture in the Italian Alps. Arch Environ Contam Toxicol. 63, 29, 2012.

33. WANG Y., LUO C.L., LI J., YIN H., LI X.D., ZHANG G. Characterization of PBDE in soils and vegetations near an ewaste recycling site in South China. Environ Pollut. 159, 2443, 2011.

34. VRKOSLAVOVA J., DEMEROVA K., MACKOVA M., ZEMANOVA T., MACEK T., HAJSLOVA J., PULKRABOVÁ J., HRÁDKOVÁ P., HANA STIBOROVÁ H. Absorption and translocation of polybrominated diphenyl ethers (PBDE) by plants from contaminated sewage sludge. Chemosphere. 81, 381, 2010.

35. US EPA. Screening Level Ecological Risk Assessment Protocol for Hazardous iste Combustion Facilities. Peer Review Draft. U.S. Environmental Protection Agency. August. 1999.

36. SHE Y.Z., WU J.P., ZHANG Y., PENG Y., MO L, LUO X.J., MAI B.X. Bioaccumulation of polybrominated diphenyl ethers and several alternative halogenated flame retardants in a small herbivorous food chain. Environ. Pollut. 174, 164, 2013

37. ZHU H.W., WANG Y., TAM, N.F.Y. Microcosm study on fate of polybrominated diphenyl ethers (PBDEs) in contaminated mangrove sediment. J. Hazard Mater. 265, (30), 61, 2014.

38. GUARDIA M.J.L., HALE R.C., HARVEY E. Detailed Polybrominated Diphenyl Ether (PBDE) Congener Composition of the Widely Used Penta-, Octa-, and DecaPBDE Technical Flame-retardant Mixtures. Environ. Sci. Technol. 40, 6247, 2006.

39. US EPA. Methods for measuring the toxicity and bioaccumulation of sediment-associated contaminants with freshwater invertebrates. EPA 600/R-94/024. Environmental Research Laboratory, Duluth, MN. 1994.

40. Environment Canada. Ecological Screening Assessment Report on Polybrominated Diphenyl Ethers (PBDEs), 2006.

41. LEMLY A.D. Evaluation of the hazard quotient method for risk assessment of selenium. Ecotox. Environ. Safe. 35, 156, 1996.

42. WU M.H., TANG L., XU G., MA J., LIU N., WANG L., LEI J.Q. Polybrominated diphenyl ethers in surface sediments from principal watersheds of Shanghai, China: levels, distribution, influencing factors, and risk assessment. Environ. Sci. Pollut. Res. 20, 2651, 2013. 
